Fermilab-TM-2639-APC

October 26, 2016

\title{
Radiation Shielding Calculations for the Booster Notcher Absorber
}

\author{
Igor Rakhno, Igor Tropin
}

\begin{abstract}
The shielding calculations for the Booster Notcher absorber were performed in order to predict the surface water activation around the absorber and effective dose at the nearest public places (in Booster gallery and atop the berm).
\end{abstract}

1. Model description

The calculations were performed with the MARS15 computer code [1]. A fragment of the inner part of the absorber is shown in Fig. 1, and Fig. 2 shows a cross section of the model with tunnel.

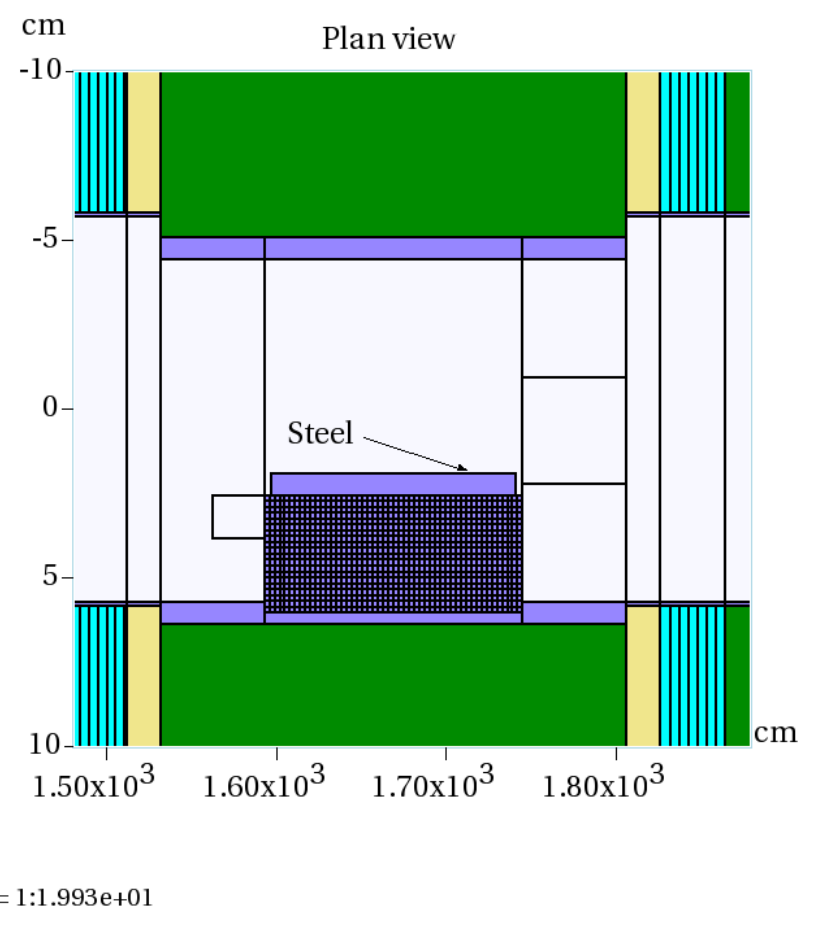

Fig. 1. A fragment of the inner part of the Booster Notcher absorber with a steel insert inside. 


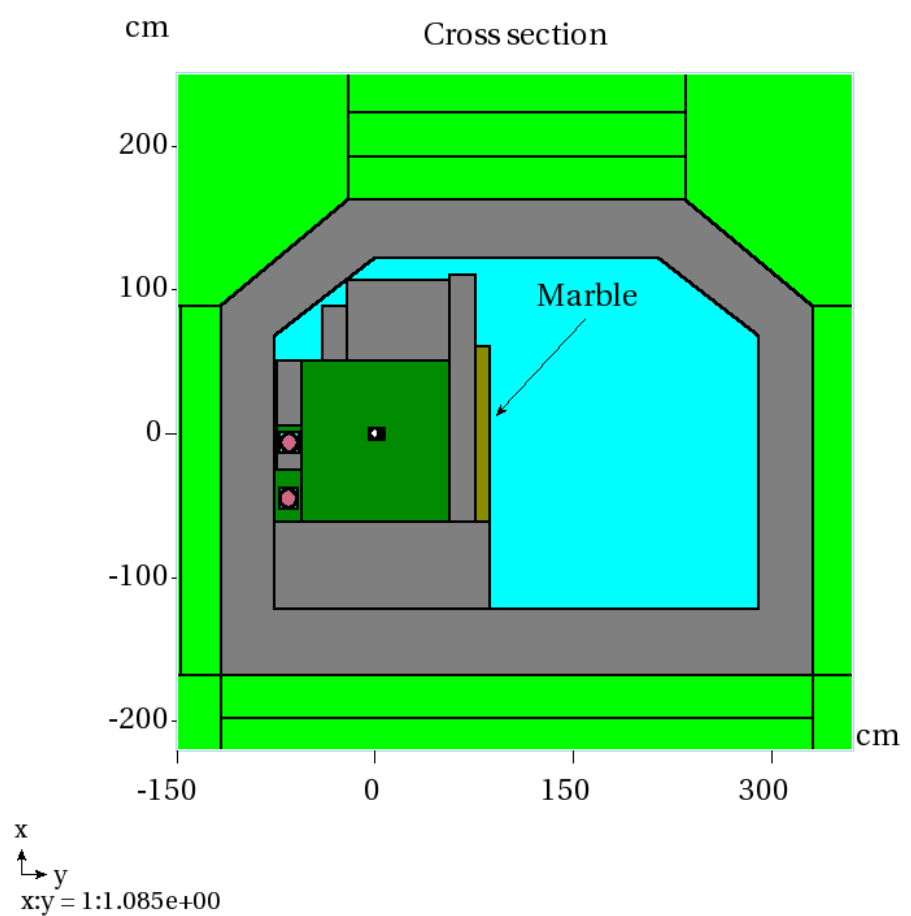

Fig. 2. A fragment of the model of the Booster Notcher absorber with tunnel.

There are three penetrations between the Booster tunnel and gallery shown in Fig. 3. All the three penetrations are alike: square steel tubes 7" by 7", steel wall thickness is $3 / 8^{\prime \prime}$, and the filling is (counting upward from the lower opening in the tunnel concrete ceiling) 1-ft air, 12-ft polybeads with effective density $0.55 \mathrm{~g} / \mathrm{cm}^{3}$, and the remaining length up to the upper opening in the Booster gallery is filled with the air. Longitudinally the first penetration is located a few inches upstream of the start of the absorber body, the second penetration is $75^{\prime \prime}$ downstream of the start of the absorber 108"-long body, and the last penetration is 56" downstream of the end of absorber body.

\section{Calculation results}

The calculation results were performed for a $400-\mathrm{MeV}$ proton beam and normalized for the beam intensity of $2.679 \times 10^{12}$ proton/second. The beam loss distribution calculated for the absorber separately [2] served as an input for our calculations.

Star density distribution around the absorber is shown in Figs. 4 and 5. 


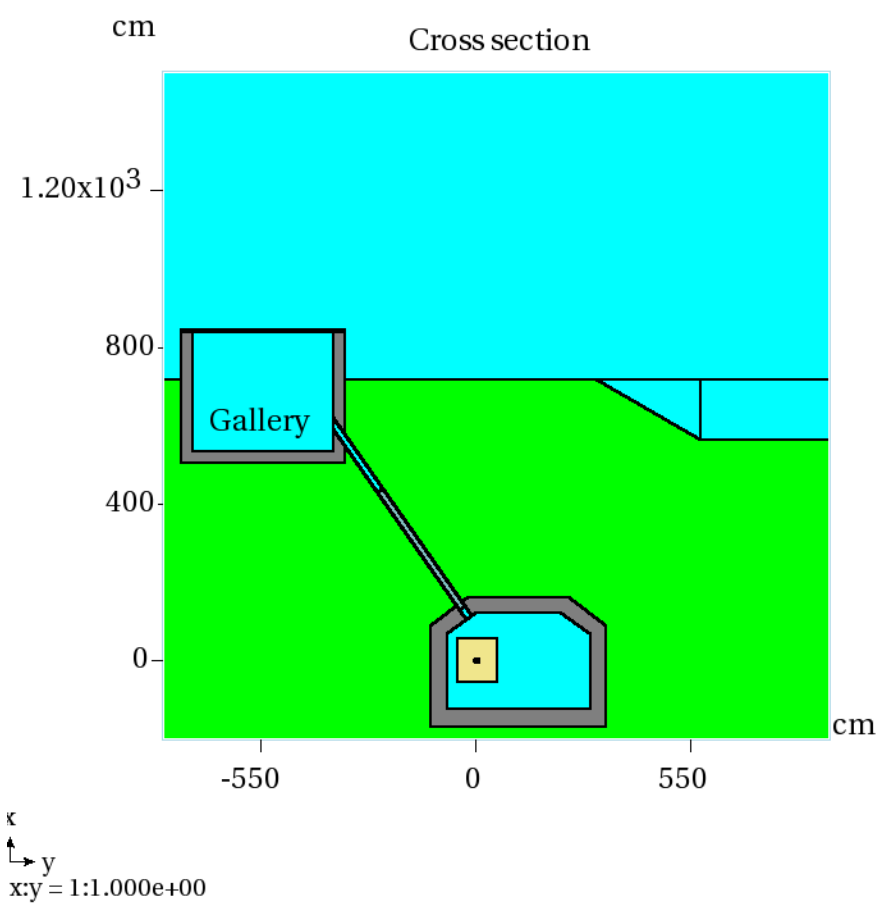

Fig. 3. A cross of the model that shows the penetrations between the Booster tunnel and gallery, as well as shielding profile above the Booster tunnel.

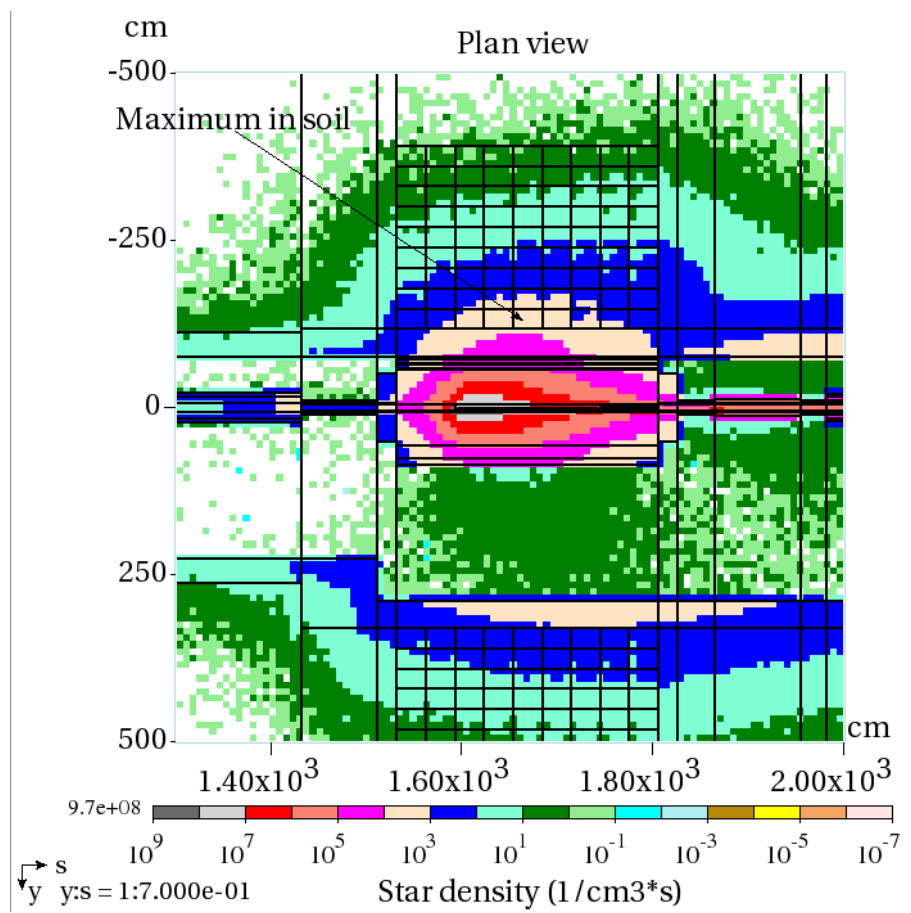

Fig. 4. Calculated star density distribution around the Booster Notcher absorber (plan view) that shows location of the maximum star density in the soil. 


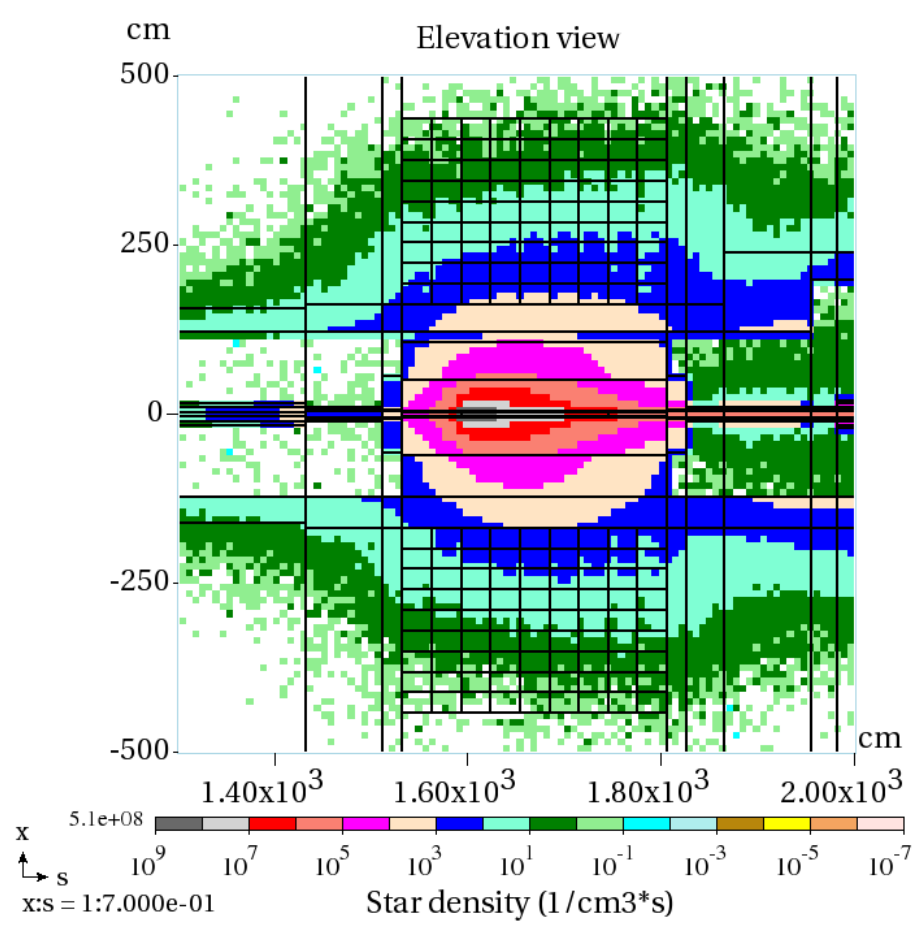

Fig. 5. Calculated star density distribution around the Booster Notcher absorber (elevation view).

The maximum predicted star density is $3140 \mathrm{star} /\left(\mathrm{cm}^{3 *} \mathrm{~s}\right)$ for a bin with linear dimension approximately $1 \mathrm{ft}$. The calculated statistical uncertainty of this value is about $5 \%$.

The calculated prompt dose distributions around the Booster Notcher absorber are shown in Figs. 6 and 7 for all the three penetrations. The prompt dose on the berm surface and in the gallery near the penetrations were calculated using the well known dose attenuation pattern for the soil approximately 10 -fold dose reduction in a 100-cm thick soil layer. The dose attenuation pattern observed in these calculations is a bit better (i.e. faster attenuation), but in order to get a conservative estimate, we use the first rule, that is 10 -fold dose reduction for each $100 \mathrm{~cm}$ of soil.

The hottest predicted location atop the berm is right above the tunnel, and the predicted dose is $10 \times^{-4} \mathrm{mSv} / \mathrm{hr}=0.01 \mathrm{mrem} / \mathrm{hr}=10 \mu \mathrm{rem} / \mathrm{hr}$.

The highest predicted dose in the gallery near the penetrations is about $5 \mu \mathrm{rem} / \mathrm{hr}$. At the penetration openings the highest predicted dose is about $20 \mu \mathrm{rem} / \mathrm{hr}$. A slight neutron streaming is observed only for the 1 st of those penetrations. 

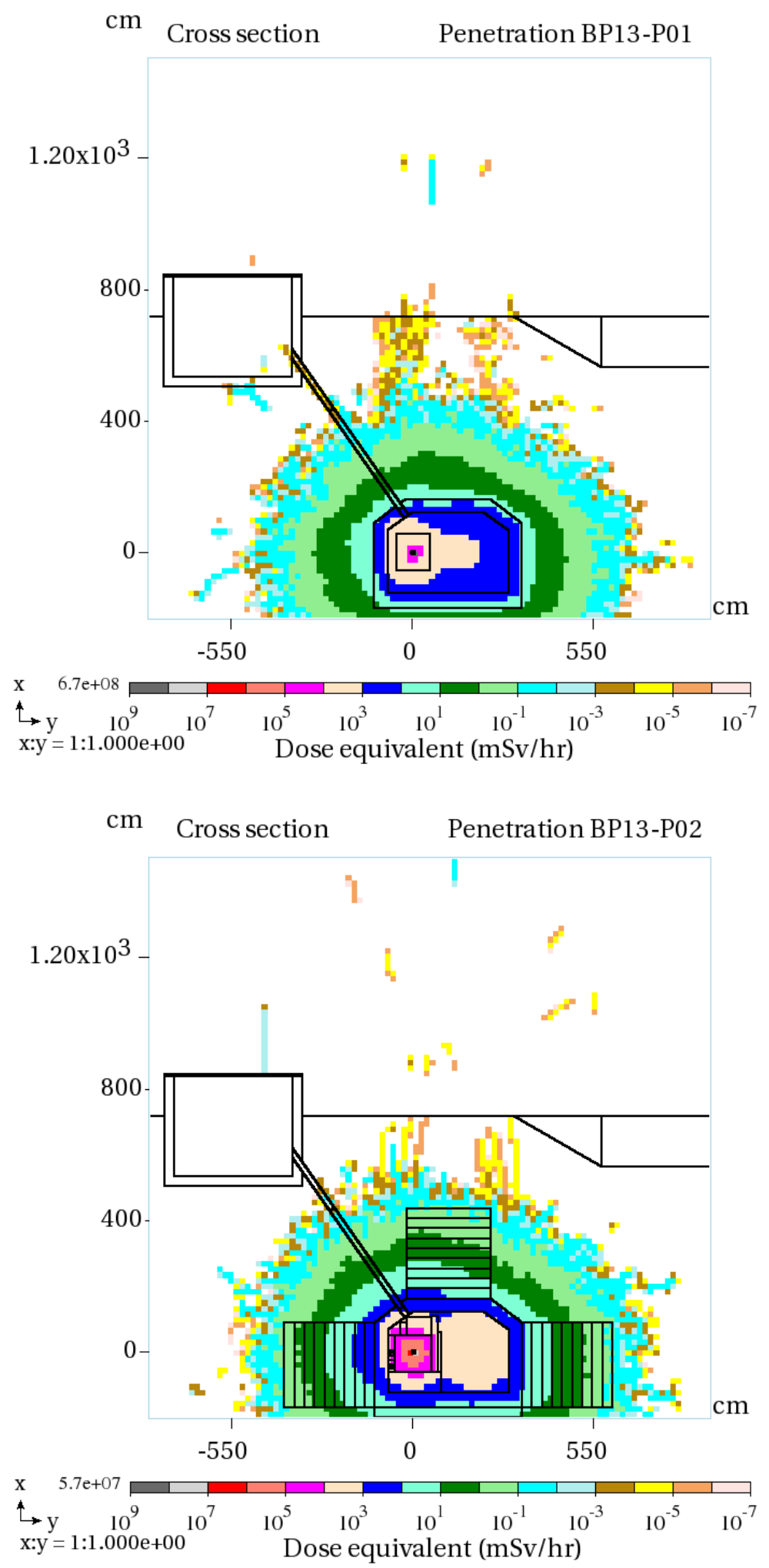

Fig. 6. Calculated prompt dose distribution around the Booster Notcher absorber at the first (top) and second (bottom) penetration. 


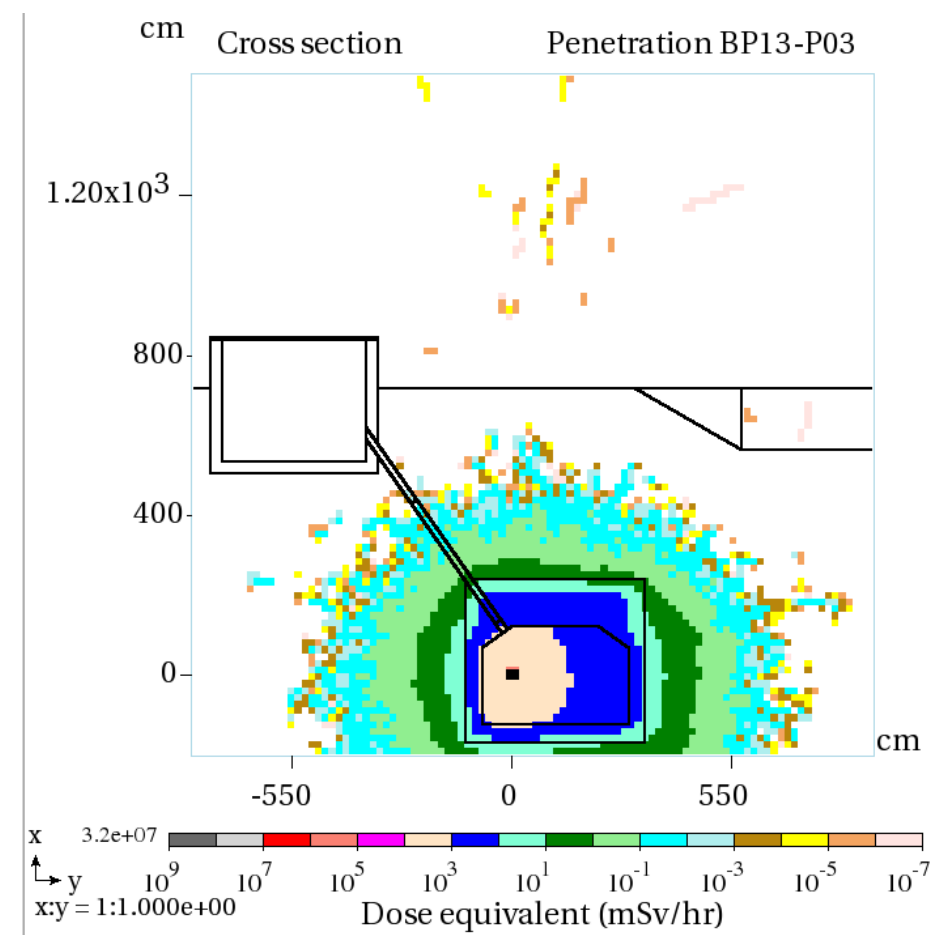

Fig. 7. Calculated prompt dose distribution around the Booster Notcher absorber at the third penetration.

\section{Acknowledgements}

Authors are thankful to Michael Vincent of ESH Department for help with the model of the area.

\section{References}

1. N.V. Mokhov, The MARS Code System User's Guide, Fermilab-FN-628 (1995); N. V. Mokhov and S.I. Striganov, MARS15 overview, Proc. Of Hadronic Shower Simulation Workshop Fermilab September 2006, AIP Conf. Proc. 896 (2007), pp.50-60; http://www-ap.fnal.gov/MARS.

2. Kiyomi Seiya of Fermilab Booster Department (private communication). 